Geopolítica(s) Revista de estudios sobre espacio y poder

ISSN: 2172-3958

\title{
Orden Mundial y tecnología. Análisis institucional desde la perspectiva geopolítica en la semiperiferia: la tecnología espacial y de misiles en Argentina y Brasil ${ }^{1}$
}

\author{
Daniel Blinder ${ }^{2}$
}

Recibido: 21 de julio de 2016 / Aceptado: 7 de julio de 2017

Resumen. El presente artículo busca definir, comprender y explicar la relación existente entre el Orden Mundial, la política exterior, y la cuestión tecnológica desde una perspectiva geopolítica. Las estructuras del Orden Mundial, las jerarquías establecidas, las relaciones de poder y los códigos geopolíticos de los Estados Nacionales le imprimen determinadas características al desarrollo tecnológico, así como sus significados hacia la política doméstica y externa. La cuestión tecnológica y su desarrollo está relacionado directamente con las políticas llevadas a cabo por las unidades estatales y otros actores del sistema internacional, pero a su vez éstas están condicionadas por el sistema internacional que los contiene, el Orden Mundial. Toda política tecnológica de un Estado es una política interna, y es también lo que se denomina política externa. En este artículo se mostrará a partir de los ejemplos de las tecnologías misilística y espacial de Argentina y Brasil cómo la política tecnológica es una política de poder, cómo se relaciona con el sistema internacional, que incluye la política exterior para su desarrollo, y que la separación exterior/doméstico explica cómo operan los gobiernos, pero no el orden geopolítico que excede la dimensión estatal.

Palabras clave: Orden Mundial; geopolítica; tecnología; semiperiferia; política exterior.

\section{[en] World Order and Technology. Institutional Analysis under a Geopolitical Perspective in the Semi-periphery: Space and Missile Technology in Argentina and Brazil}

\footnotetext{
Abstract. This article aims to define, understand, and explain the existent relationship between World Order, foreign policy and the technology issue under a geopolitical scope. The structures of the World Order, hierarchies, the power and geopolitical codes of Nation States shapes certain characteristics to technology development on domestic and foreign policy. Technology issue and development is directly linked with policies undertaken by states and other actor of international system, system which is a part of the Order. Every technology policy of a state is a domestic policy and a foreign one. This article shows with examples of missile and space technologies on Argentina and Brazil how technology policy is also power politics, how is related with the international system, and how foreign and

1 Agradezco a la Universidad Nacional de San Martín por el constante apoyo e incentivo para investigar sobre Tecnología, Geopolítica y Relaciones Internacionales.

2 Becario posdoctoral CONICET. Profesor de Relaciones Internacionales y Tecnología en la Universidad Nacional de San Martín (UNSAM) y de Geopolítica en la Universidad de Buenos Aires (UBA).

E-mail: dblinder@unsam.edu.ar
} 
domestic issues explain the behavior of government but not the geopolitical order, that exceeds Nation State dimension.

Keywords: World Order; geopolitics; technology; semiperiphery; foreign policy.

\section{[pt] Ordem Mundial e tecnologia. Análise institucional na perspetiva geopolítica na semiperiferia: a tecnologia espacial e de mísseis na Argentina e no Brasil}

Resumo. O presente artigo busca definir, compreender e explicar a relação existente entre a Ordem Mundial, a política externa e a questão tecnológica sob a ótica da geopolítica. As estruturas da Ordem Mundial, as hierarquias estabelecidas, as relações de poder e os códigos geopolíticos dos Estados Nacionais imprimem determinadas características ao desenvolvimento tecnológico, assim como seus significados para a política doméstica e a externa. A questão tecnológica e seu desenvolvimento estão relacionados diretamente com as políticas levadas a cabo pelas unidades estatais e outros atores do sistema internacional, mas ao mesmo tempo estas unidades estão condicionadas pelo sistema internacional que as contém, a Ordem Mundial. Toda política tecnológica de um Estado é uma política interna, e também o que se denomina política externa. Neste artigo se mostrará a partir dos exemplos das tecnologias de mísseis e espacial de Argentina e Brasil de que modo a política tecnológica é uma política de poder, como se relaciona com o sistema internacional, que inclui a política externa para seu desenvolvimento, e que a separação exterior/doméstico explica como operam os governos, mas não a ordem geopolítica que ultrapassa a dimensão estatal.

Palavras-chave: Ordem Mundial; geopolítica; tecnologia; semiperiferia; política externa.

Sumario. Introducción. 1. Política exterior y código geopolítico. 2. Instituciones como Orden. 3. Tecnología y (geo)política. 4. Casos: política exterior como factor determinante. 4.1. El caso espacial argentino. 4.2. El caso espacial brasilero. 4.3. El caso misilístico argentino. 4.4. El caso misilístico brasileño. 4.5. Status quo militar y tecnológico. 4.6. Institucionalidad internacional argentina. 4.7. Institucionalidad internacional brasileña. Reflexiones finales. Bibliografía.

Cómo citar: Blinder, Daniel (2017) "Orden Mundial y tecnología. Análisis institucional desde la perspectiva geopolítica en la semiperiferia: la tecnología espacial y de misiles en Argentina y Brasil”" Geopolitica(s). Revista de estudios sobre espacio y poder, vol. 8, núm. 2, 177-202.

\section{Introducción}

El presente trabajo busca comprender el vínculo entre el Orden Mundial, la política exterior y la cuestión tecnológica desde una perspectiva geopolítica. En ese sentido, el Orden Mundial, sus estructuras, jerarquías, relaciones de poder y códigos geopolíticos de los Estados Nacionales le imprimen determinadas características al desarrollo tecnológico, sus significados hacia la política doméstica y externa. Entendemos la cuestión tecnológica como problema. Analizamos el caso espacial y misilístico por ser paradigmático, de uso dual, un tema sensible de la agenda global, regulado internacionalmente por instituciones, y por ser una tecnología que implica un nivel importante de desarrollo de tecnologías de punta implicadas.

Así, la cuestión tecnológica y su desarrollo está relacionada directamente a las políticas llevadas a cabo por las unidades estatales y otros actores del sistema internacional, pero a su vez estas están condicionadas por el sistema internacional que los contiene, el Orden Mundial. La relevancia del presente trabajo radica en 
explicar, desde una perspectiva geopolítica, la relación del Orden Mundial con la cuestión tecnológica, cuya posibilidad de desarrollo local/nacional está supeditada y limitada por situaciones de índole global. Una política tecnológica es una política pública realizada por un organismo estatal ${ }^{3}$. Toda política de desarrollo tecnológico tiene doble faz, pues es una política interna pero también externa. Los principales hallazgos aquí presentados buscarán demostrar que la política tecnológica es una política de poder, que está relacionada con el sistema internacional, que comprende a la política exterior para su desarrollo, y que la separación exterior/doméstico explica cómo operan los gobiernos nacionales, pero no el orden geopolítico que excede la pura dimensión estatal.

Los ejemplos utilizados son de las tecnologías misilística y espacial de Argentina y Brasil, puesto que son dos tecnologías sensibles, que suscitan el interés de las potencias militares y económicas que consiguieron primero estos desarrollos, son tecnologías cuyo marco de regulación internacional es muy importante y estricto, mediante instituciones, y son dos desarrollos generados desde dos países semiperiféricos. No trabajaremos aquí casos de países centrales porque estos determinan qué tecnologías son sensibles y cuáles no, han sido los primeros en obtenerlas y fabricarlas, y si hiciéramos una metáfora marxista o estructuralista, su política está empeñada en construir una estructura tecnológica y una superestructura institucional que las legitime y regule.

Los países de la periferia se ven más afectados por las regulaciones internacionales, debido a que estos marcos institucionales fueron generados, concretamente, después de que los pioneros obtuvieran el monopolio en el campo nuclear y espacial. Las regulaciones promueven el uso pacífico y el control de la proliferación. Las instituciones internacionales buscan favorecer el buen uso de estas tecnologías entre potencias, pero también entre aquellas que no lo son y que aspiran a desarrollarlas. Y buscan que no se multipliquen nuevos miembros. No obstante, aquí no busca reforzarse el argumento del enfoque realista de las Relaciones Internacionales, es decir, que la tecnología es un atributo de poder del Estado, sino que, por el contrario, se busca demostrar mediante los casos escogidos cómo se manifiesta la geopolítica a través del Orden Mundial. La tecnología nuclear y espacial en Argentina y Brasil son dos casos ejemplares cuya relevancia radica en ser dos países con características similares, una historia comparable de capacidades técnicas e industriales, y pertenecientes a similares e interdependientes procesos geopolíticos de América del Sur.

Este texto analizará primero la relación entre política exterior y geopolítica, definirá qué se entiende por estos conceptos, los códigos geopolíticos, y las categorías de centro, periferia y semiperiferia. Seguidamente, se explicará el rol de las instituciones internacionales en el contexto del Orden Mundial, y la constitución de un orden geopolítico. Posteriormente, se explicará la relación entre la tecnología y la geopolítica, cuya importancia se comprende a partir del concepto de madurez tecnológica. Luego, se analizarán los dos casos de países semiperiféricos en materia nuclear y espacial/misilística para entender el funcionamiento sobre estos nuevos actores políticos y el rol que juega la política exterior. Finalmente, se realizará un

Asumimos que el Estado tiene el rol de generador de políticas, por acción manifiesta, por delegación en sectores privados, o por omisión. 
balance sobre lo trabajado en este artículo, en el cual se concluye que para pensar el desarrollo tecnológico es menester tener en cuenta la variable exterior, el contexto geopolítico en cual se asienta históricamente esta política. Pensarlo desde la perspectiva semiperiférica otorga en este tema un enfoque distinto, puesto que desde allí se pueden observar con más detalle las constricciones institucionales del Orden Mundial. Un país central — para parafrasear a cualquier autor realista — es hacedor de reglas, no tomador de ellas.

\section{Política exterior y código geopolítico}

Podemos afirmar que el Orden Mundial es una institución con instituciones: esto quiere decir que el orden es practicado, y aceptado como legítimo debido a que es hegemónico, ejercido también en última instancia con una espalda de poder militar por parte de los Estados que rigen el Orden ${ }^{4}$. Pero también hay instituciones organizadas y visibles que ejercen y regulan el poder en el sistema internacional ${ }^{5}$. Kissinger, por ejemplo, en su clásico libro Diplomacia explica que está realizado en base a un orden creado en la posguerra (Kissinger, 2001), institucionalizado con los vencedores, "las Naciones Unidas", el Consejo de Seguridad que les dio asiento a las potencias vencedoras, entre ellas el mayor poder del planeta y vencedor en la contienda de la Guerra Fría, los Estados Unidos, quien lidera el sistema interestatal en base al ejercicio de su hegemonía.

De acuerdo a Immanuel Wallerstein, el sistema-mundo es un sistema mundial, un sistema social, que tiene límites, estructuras, grupos, miembros, reglas de legitimación, y coherencia (Wallerstein, 2005: 489). El sistema mundial, según el autor, es un "modo económico [que] se basa en el hecho de que los factores económicos operan en el seno de una arena mayor de lo que cualquier entidad política puede controlar totalmente" (Wallerstein, 2005: 491), yendo más allá de las estructuras de los Estados-Nación, y forma espacios centrales, semiperiféricos y periféricos. Decimos que son Estados centrales aquellos más poderosos $-\mathrm{y}$ políticamente- en el sistema internacional. Esto quiere decir que son los países más dinámicos y desarrollados, económica y tecnológicamente, del sistema capitalista, pero que también presentan una estructura estatal con capacidad de influir en el sistema internacional de Estados, con un importante poder militar y diplomático. Son periféricos los Estados-nación que no tienen poder económico ni político. Por ello,

4 La teoría realista de las Relaciones Internacionales postula que en el sistema internacional impera la anarquía, es decir, que no existe poder alguno por arriba de los Estados. Al existir tal anarquía en el sistema, los Estados se valen de su poder y su capacidad de ejercer alianzas para lidiar con los otros países. En la interacción de los poderes se produce un sistema multipolar (como en el s. XIX), bipolar (como en la Guerra Fría del s. XX) o unipolar (como en la década de 1990 con los Estados Unidos vencedores de la contienda este-oeste. Asimismo, entre las potencias contendientes se produce un equilibrio de poder, basado en el límite y balance de las potencias económica y militarmente. Todo esto es sin dudas una construcción artificial sin instituciones visibles, pero podemos afirmar aquí que constituyen una institución en sí mismas, ya que son prácticas regulares y reglas aceptadas de un orden por parte del Estado frente a las otras unidades estatales.

5 Los organismos internacionales como las Naciones Unidas, Banco Mundial, FMI, otros agrupamientos de países con distintos temas para la gobernanza mundial.

6 United Nations o Allies eran los nombres de los Aliados en la Segunda Guerra. Ver Declaración de las Naciones Unidas de 1942. Disponible en URL: <http://avalon.law.yale.edu/wwii/washc016.asp>. Visitado el 23 de febrero de 2016 . 
son poco relevantes en el sistema internacional interestatal, y poco relevantes económicamente. No obstante, son parte del sistema mundial y aportan al mismo principalmente materias primas y productos primarios. Son semiperiféricos aquellos países de la periferia con capacidad industrial, científica y tecnológica. Los Estados semiperiféricos tienen más relevancia política en el sistema interestatal que los periféricos ${ }^{7}$.

La semiperiferia combina simultáneamente procesos del centro y de la periferia, con un Estado activo en el desarrollo, cierto nivel de intervención política en las decisiones económicas, pero en un entramado periférico y con rasgos de limitaciones estructurales de la industria, dependencia del mercado externo, bienes de capital y divisas, así como también una desigualdad social propia de estas locaciones territoriales. La tecnología en la periferia es obsoleta, mientras que en el centro es avanzada; en la semiperiferia se producen dinámicas de crecimiento y desarrollo técnico combinando ambas situaciones (Taylor \& Flint, 2002: 21-22). Así, un país de la semiperiferia presenta códigos geopolíticos distintos de aquellos países del centro, códigos que podemos definir como "un conjunto de supuestos estratégicos que elabora un gobierno sobre otros Estados para orientar su política exterior" (Taylor \& Flynt, 2002: 99).

En esa línea, un código geopolítico es una imagen creada por el Estado para hacer una imagen parcializada del territorio, tema de agenda, institución o Estado sobre el cual se va intervenir políticamente. Hay códigos locales, regionales o globales de acuerdo a la escala. Y ellos se conforman desde la percepción local, la política doméstica, las identidades de los actores desde la historia política, social, económica e institucional. Así existe una imaginación geopolítica de los actores que tienen una visión del mundo y de su funcionamiento. En consecuencia, existe un discurso geopolítico acerca de cómo son leídos los acontecimientos políticos y económicos del sistema-mundo, y cómo es representado el poder en el espacio (Agnew, 1995: 46-47; Agnew, 2005: 160).

Los países, y por lo tanto el lugar que ocupan en el mundo son y están en el centro del sistema-mundo, su semiperiferia o periferia. "Las instituciones de los lugares concretos sirven de medidoras de poder" dicen Taylor \& Flint (2002: 42). Siguiendo a estos autores: entender la política es entenderla en clave geográfica puesto que el espacio es un área en disputa. "El espacio nunca constituye un mero escenario donde se desarrollan los acontecimientos: ninguna disposición espacial tiene nada de neutral" (Taylor \& Flint, 2002: 42). Entendemos por lo tanto a la geopolítica como el estudio de la distribución geográfica del poder entre los Estados, tanto como los supuestos, designaciones e interpretaciones geográficas que intervienen en la política en todas las escalas geográficas (Agnew, 2005: 159; Taylor \& Flint, 2002: 416).

\footnotetext{
"El proceso en marcha de una economía-mundo tiende a aumentar las distancias económicas y sociales entre sus distintas áreas en el mismo proceso de su desarrollo. Un factor que tiende a enmascarar este hecho es que el proceso de desarrollo de una economía-mundo trae consigo adelantos tecnológicos que hacen posible la expansión de sus márgenes. En este caso, regiones particulares del mundo pueden cambiar su papel estructural [...] La arena externa de un Siglo se convierte a menudo en la periferia - o semiperiferia - del siguiente. Pero también [...] los Estados del centro pueden convertirse en semiperiféricos y los semiperiféricos en periféricos" (Wallerstein, 2005: 493).
} 


\section{Instituciones como Orden}

¿Qué es una institución? Las instituciones son las reglas de juego en una sociedad, y que dan forma a la interacción humana, de acuerdo a North (1990: 3). Las instituciones reducen la incertidumbre en el comportamiento político, social o económico porque dan previsibilidad al comportamiento mediante reglas. Hay instituciones formales e informales (North, 1990: 4) cuyo resultado redunda en un tipo de orden. La institución política más importante y poderosa en términos del poder y de su capacidad de regulación social y económica es el Estado-Nación. El Estado, en palabras de Weber es una comunidad humana que al interior de un determinado territorio reclama para sí con éxito el monopolio de la coacción física legítima. Política es entonces la participación o la influencia en las decisiones y distribución de poder en el Estado o entre los Estados. "El que hace política, aspira al poder" (Weber, 2002: 1056).

El Estado, en consecuencia, es una relación social y política, por lo que implica relaciones de poder, $\mathrm{y}$

una condensación de fuerzas políticas que operan fuera y dentro del Estado [...] A su vez, el poder del Estado puede entenderse como una relación de poder que es mediada por y a través de un conjunto institucional. El poder no es ejercido por el Estado como tal. El Estado no es un sujeto. Tampoco se origina enteramente en el Estado, sino que depende del equilibrio de fuerzas [...] en la sociedad [...] como dentro de los propios aparatos del Estado (Jessop, 2008: 7).

Así se configura un orden hegemónico, que en términos de Gramsci es un liderazgo político, cultural, intelectual, y económico en un espacio-tiempo determinado.

La hegemonía es coacción y consenso, implica aceptación del orden, la constitución de un bloque histórico en el cual coinciden el liderazgo de aquellos que ejercen el poder y relaciones de producción dadas (Cox, 1996). Así,

las instituciones proveen maneras de enfrentar los conflictos y minimizar, de ese modo, el uso de la fuerza. Hay un reforzamiento potencial en las relaciones materiales de poder subyacentes a cualquier estructura, en el cual el más fuerte puede dar una paliza al débil si piensa que es necesario. Pero la fuerza no debe ser utilizada con el fin de asegurar el dominio del fuerte hasta el límite de que el débil acepte las relaciones de poder prevalecientes como legítimas. Esto lo puede hacer el débil si el fuerte ve su misión como hegemónica y no meramente dominante o dictatorial, esto es, si desea hacer concesiones que puedan asegurar la aquiescencia del débil respecto a su liderazgo y si puede expresar su liderazgo en términos de intereses universales o generales, más que como mero apoyo a sus propios intereses particulares (Cox, 1994: 145).

Estado, mercado, y sociedad se presentan ante nosotros, como instituciones que determinan las formas del poder. El primer intento de vincular al cambio tecnológico con el cambio institucional fue Marx, quien sostenía que el cambio en las fuerzas productivas - sinónimo de tecnología - modificaba necesariamente las relaciones de producción en el sistema capitalista, y por ello la superestructura jurídico-política. En las relaciones de centro-periferia también hay un grado de institu- 
cionalización formal e informal, cuyo resultado deviene en que los países periféricos son víctimas de una estructura institucional (formal o informal) que previene su desarrollo desde lo internacional, y también en el propio campo de acción soberano nacional (North, 1990: 132-134).

Las instituciones son las portadoras del sentido de la naturaleza de las relaciones de fuerza en un orden dado, constituyendo la hegemonía la cristalización de esas relaciones. La forma de Estado que predominó hacia la década de 1970 la podemos denominar fordista, caracterizada por un Estado de Bienestar keynesiano que arbitraba las relaciones entre capital y trabajo, y distribuía socialmente los recursos con una fuerte matriz de intervención estatal. Luego, la coyuntura global, los cambios tecnológicos y la transnacionalización de la economía, comenzaron a traer otras perspectivas en las cuales el Estado se retiraba y daba lugar al mercado como actor más poderoso, período que se conoce como neoliberalismo o posfordismo, invirtiendo las relaciones de fuerza en la economía-mundo (Hirsch, 1996). Jessop (2008:117) denominó esta nueva forma institucional como Estado competitivo shumpeteriano ${ }^{8}$. Es competitivo en tanto que "trata de garantizar el crecimiento económico dentro de sus fronteras y de asegurar ciertas ventajas competitivas para los capitales establecidos dentro de las mismas, aunque operen en el extranjero, promoviendo las condiciones $[\ldots]$ consideradas esenciales para triunfar en competencia con otros actores y espacios económicos localizados en otros Estados" (Jessop, 2008: 118). Es aquello que Hirsch (1996: 66) denominó Estado Nacional de Competencia9.

El posfordismo está basado en una economía apoyada en el conocimiento. La hegemonía de Estados Unidos en el campo científico-tecnológico está fundada en una economía basada en el conocimiento, sustentado por el dominio sobre los regímenes internacionales y la supremacía militar vinculada a esta (Jessop, 2008: 126). Por el contrario, para los países periféricos o semiperiféricos en esta situación se ven debilitados, pues al abandonar los Estados el control sobre la gestión económica para hacerse más competitivos, ven paradojalmente reducidas más aún su autonomía y capacidad de gobernanza sobre los propios procesos bajo su soberanía. Pero también ocurre en los países centrales, cuyo liderazgo estatal promueve y direcciona la investigación y el desarrollo, el capital de riesgo, y los entramados institucionales para crear e innovar, y generar nuevos mercados de liderazgo mundial, promoviendo rentas tecnológicas que consolidan la posición de ventaja a las empresas de estos países (Jessop, 2008: 154, 156).

Las coyunturas posbélicas de las guerras entre potencias mundiales tienen una impronta determinante para los vencedores, puesto que tienen la oportunidad de forjar el orden internacional. Esta es la aproximación que da Ikenberry (2001: 3) para explicar los órdenes de posguerra en la modernidad ${ }^{10}$. Aquel Estado que gana

8 Schumpeter planteaba el concepto de destrucción creativa para explicar el cambio tecnológico. Básicamente, mediante la destrucción de lo viejo a partir de una innovación tecnológica es que se produce el cambio (Schumpeter, 1971)

9 Este concepto refiere a la adecuación legal, política y económica de los países, desregulando la economía, para facilitar la inversión y llegada de capitales, haciendo más atractivo al Estado por su rentabilidad: ya sea por bajos salarios, bajos o nulos impuestos, facilidades administrativas, etc. (Hirsch, 1996).

101648 (Tratado de Westfalia), 1713 (Tratado de Ultrecht), 1815 (Congreso de Viena), 1919 (Tratado de Versalles) y 1945 (Conferencia de Yalta - Organización de Naciones Unidas) fueron los grandes acuerdos diplomáticos posbélicos que crearon un orden de grandes potencias, que incluyó aspectos de ordenamiento geopolíti- 
una gran guerra tiene un gran poder no solo para imponer su voluntad, en el orden mundial, sino que también puede transformar el sistema restringiendo su poder, pero ganando influencia, construyendo un entramado institucional duradero y favorable a sus intereses nacionales, que es una mesura estratégica. Esto involucra a los derrotados y a las otras naciones en la gobernanza mundial, facilita la cooperación, el involucramiento en los asuntos globales, el compromiso y, por lo tanto, en la legitimación. Conjuntamente, sirve como control político por parte del forjador del orden y su liderazgo en el mismo (Ikenberry, 2001: 4-5) ${ }^{11}$.

Agnew (1995: 15) describe al orden geopolítico como "reglas rutinizadas, instituciones, actividades y estrategias por las cuales la economía política ha operado en diferentes períodos". La cuestión del orden es geopolítica porque se refiere a los elementos geográficos del orden aludido ${ }^{12}$ :

Cualquier orden geopolítico es una mixtura de cohesión y conflicto entre actores, un sistema de gobernanza organizado que define los actores, las reglas, los principios de interacción, y compartidas concepciones entre los actores acerca del comercio, la fuerza y la diplomacia: lo que incluye a las instituciones formales internacionales, regímenes, etc., que cubren un amplio espectro del comportamiento entre los actores (Agnew, 1995: 16).

¿Cómo influye este orden mundial sobre el desarrollo tecnológico? Dijimos que las cuestiones de la política internacional están geocentradas, las relaciones de Estado a Estado son un dato más - la relación entre instituciones que controlan o regulan en distinto grado instancias económicas y sociales que suceden en sus territorios - pero algunos de ellos presentan características de mayor poderío industrial, técnico, militar, económico y de influencia política, y sus políticas externas condicionan y moldean la de los otros.

\section{Tecnología y (geo)política}

No existe una bibliografía académica unificada que reúna los conceptos de geopolítica y tecnología. Existen distintas corrientes de pensamiento geopolítico y diferentes abordajes de la problemática tecnológica, mayormente desde los estudios sociales de la ciencia y la tecnología, la economía o la cooperación internacional en

co, militar, económico (Ikenberry, 2001: 3). Aquí se establecieron las reglas de juego, instituciones, que forjaron el comportamiento de los actores involucrados. Para Agnew (1995) estos fueron tres, puesto que observa grandes ciclos económicos además de las relaciones de fuerzas: 1815-1875, 1875-1945, y 1945-1990. El último presenta una serie de instituciones de regulación económica como el GATT, FMI, o Banco Mundial que ordenaron la economía internacional.

11 Cuando la hegemonía tras una gran victoria en una guerra declina, las instituciones sustentan el orden y la cooperación. Pero son las instituciones críticas al principio de la hegemonía o inmediatamente después de la victoria, al establecer un orden y asegurar la cooperación entre Estados que no se encuentran en una relación simétrica e igual en el plano internacional (Ikenberry, 2001: 17)

12 Esto incluye la relativa centralidad del Estado-Nación en cuestiones territoriales para las cuestiones socioeconómicas, la naturaleza de las jerarquías entre los Estados, la dimensión espacial que incluye a otros actores no estatales, la conexión espacial entre los actores del orden geopolítico, y los efectos condicionantes de la tecnología civil o militar — de parte de un Estado sobre otros — en términos de seguridad militar y económica (Agnew, 1995: 15). 
relaciones internacionales. No obstante, pensar la política desde lo territorial y la cuestión tecnológica ha sido un eje con el cual algunos investigadores abordaron el problema. Los Estados han estado siempre embarcados en una carrera de competencia tecnológica íntimamente vinculada a la política. Dicha concurrencia, que tenía que ver con la productividad económica de los países, muchas veces acababa enlazada a lo militar:

Las naciones que se preocupan por su posición en el mundo son más proclives a sufrir del efecto Sputnik, el descubrimiento de que la sociedad ha quedado atrasada en materia de tecnología, y en consecuencia se siente amenazada [...]. En alguna medida, un poco de competencia entre Estados es buena para el progreso tecnológico. Pero, sin embargo, la competencia económica o política, podría degenerar en una tendencia hacia la expansión militar, la guerra, que restringiría toda ganancia de competencia política por el desarrollo de la propia técnica (Mokyr, 1990).

Opuestamente, Werner Sombart en su libro Guerra y Capitalismo planteaba:

La guerra no ha destruido solo el régimen capitalista, la guerra no ha entorpecido solo el desarrollo capitalista: lo ha fomentado igualmente [...] Para los Estados modernos, esto no hará falta justificarlo, son solo la obra de las armas; su exterior, sus límites, no menos que su articulación interna; la administración, la hacienda, se han desarrollado inmediatamente en la realización de empresas bélicas en sentido moderno (Sombart, 1943: 23).

Sombart señalaba "la doble faz de la guerra, que por una parte aquí destruye, pero por otra allí edifica" (Sombart, 1943: 27): la demanda agrícola para la provisión de alimentos, estandarización de los uniformes, de los armamentos, de los calibres, y la innovación tecnológica para la guerra llevó a una estandarización y homogeneización de la vida social, y a la necesidad de estatizar o burocratizar los asuntos militares (Sombart, 1943: 116, 123).

En el Estados Unidos del siglo XX, ciertos desarrollos industriales de alta tecnología han sido motores del desarrollo y el poder económico, militar, e internacional, y conjuntamente estos desarrollos han estado a la vanguardia de la innovación de la economía mundial:

La cuestión de las tecnologías maduras constituye un problema importante. Como un campo de tecnologías comerciales, que inicialmente recalaron fuertemente en investigación y desarrollo militar y adquisiciones para la defensa, la dependencia de estas tecnologías comerciales y maduras con aquellas vinculadas a las de uso bélico ha tendido a declinar. El flujo del conocimiento tecnológico podría ser revertido, de un spin-off a un spin-on ${ }^{13}$ (Ruttan, 2006: 5).

13 El concepto de spin-off refiere a un producto derivado de otro en el proceso de investigación y desarrollo, y el de spin-on a un cambio, un giro en el proceso. Por eso el autor habla de la importancia de las tecnologías vinculadas inicialmente a lo militar, puesto que no solo son derivadas, sino que también son innovadoras. 
Ruttan estudia tecnologías de propósito general —aquellas que de su desarrollo se integran o desarrollan nuevas tecnologías - en el contexto industrial estadounidense: las partes intercambiables y la producción en masa, los aviones comerciales y militares, la energía nuclear y eléctrica, computadoras y semiconductores, la internet, la industria espacial (Ruttan, 2006: 7). Todas estas tecnologías tienen la característica de haber alcanzado la madurez tecnológica, que llega cuando después de un rápido o explosivo desarrollo de la fase inicial de la trayectoria de una tecnología, esta comienza un período de estancamiento o madurez.

No obstante, el liderazgo de éstas presenta a quien las posea como a la vanguardia de la tecnología. Entonces, en el camino desde la producción en masa hasta la tecnología espacial, del pasaje de la explosión de una tecnología hasta su maduración existe una tendencia en la cual estas tecnologías se complementan en su uso: la tecnología espacial hace uso de la internet, los semiconductores y la informática, la energía nuclear, la aviación, y la industria de producción en masa (Ruttan, 2006: 167-171). Toda tecnología es de uso dual. Esencialmente, la doble posibilidad de uso radica en cómo será empleada. Entendemos a la tecnología como todo proceso social por el cual se generan dispositivos técnicos para distintos usos, y que en dicho proceso participan distintos actores (científicos, ingenieros, demandantes y usuarios de soluciones tecnológicas, políticos, empresarios). El modo en que la tecnología sea empleado finalmente, dependerá del usuario final. Puede ser utilizada con fines pacíficos o militares.

Las decisiones políticas en países que se encuentran en contextos semiperiféricos se ven envueltas y condicionadas por relaciones de poder globales, cristalizadas en instituciones. Las instituciones que regulan la actividad tecnológica limitan la capacidad de acción de un país, pero, asimismo, un país que busca obtener capacidades tecnológicas necesita involucrarse en estos sistemas institucionales, sin cuya participación sufrirían toda clase de presiones para limitar directamente las políticas tendientes a adquirir capacidades. Las tecnologías sensibles, especialmente aquellas de uso bélico son necesariamente objeto de esta trama para generar y sostener este Orden Mundial. Las tecnologías maduras, y su posible utilización tanto bélica como comercial, adquieren una dimensión geopolítica en la que las pocas unidades estatales que pueden producirlas, buscan aprovechar los beneficios económicos de la venta de los servicios que estas pueden ofrecer, pero también de las posibilidades que ofrecen para un eventual uso en conflictos armados.

Con esto no decimos que cualquier país semiperiférico que obtenga alguna de estas tecnologías tendrá la capacidad de vencer comercialmente a un país más poderoso. Pero su oferta sí podrá satisfacer una demanda comercial, compitiendo en mercados mundiales de alta calidad. Eventualmente, la diversificación tecnológica llevará al desarrollo nacional y el camino de un Estado de la semiperiferia al centro. Asimismo, no decimos con esto que contar con el manejo bélico de estas tecnologías vaya a suponer necesariamente la derrota militar de un país hegemónico. Sin embargo, podría desestabilizar el Orden Mundial que este país o países centrales generaron. Estudiar los casos de tecnología espacial y misilística en países como Argentina y Brasil puede arrojar luz sobre la geopolítica del Orden Global operando sobre desarrollos tecnológicos nacionales. 


\section{Casos: política exterior como factor determinante}

¿Por qué estudiar los casos tecnológicos de Argentina y Brasil como ejemplos de geopolítica, tecnología y política exterior en contextos periféricos? Porque ambos países sudamericanos son el Sur geográfico, tienen características de semiperiferia por su nivel de desarrollo industrial, y en ambos casos la cuestión tecnológica atraviesa el Orden Mundial con efectos en la geopolítica, el desarrollo y las decisiones de política tomadas en el ámbito interno y externo ${ }^{14}$. Durante la década de 1980 tuvieron lugar los primeros pasos del proceso de integración entre Argentina y Brasil, con los gobiernos de Alfonsín y Sarney, dejando atrás años de rivalidades geopolíticas. La participación en foros latinoamericanos, el control de la proliferación nuclear y la creación de una zona de paz en el Atlántico Sur fueron algunos de los avances que se produjeron. Sin embargo, en la década de 1990 la política exterior de ambos países cambia debido a los procesos de política internacional pos Guerra Fría (Saraiva \& Tedesco, 2001).

La nueva política exterior de la Argentina estaba basada en dos ideas fuerza, el realismo y el pragmatismo. Esto significaba que el sistema internacional sería entendido tal cual este era más que como debería ser, lo que dejaba a la Argentina en un lugar de marginalidad. Conjuntamente, una nueva relación con los Estados Unidos debía ser el curso de acción, puesto que así lo indicaba esta lectura de la realidad, y era necesario actuar pragmáticamente en consecuencia (Saraiva \& Tedesco, 2001). Era aquello que Escudé había acuñado con Realismo Periférico (Escudé, 1992). Se restablecieron, en ese sentido, las relaciones diplomáticas con el Reino Unido, avanzando, de acuerdo a la lectura política de la época, hacia una inserción en el mundo, con claras señales a la Unión Europea y a los estadounidenses (Saraiva $\&$ Tedesco, 2001). La política hacia el misil Cóndor, las Fuerzas Armadas, la apertura económica, las potencias, y la firma y ratificación de tratados internacionales relacionados a la no proliferación ayudaron a la modificación del perfil nacional en la arena global.

El caso de la política externa de Brasil es distinto, pues no sufrieron con el golpe militar un proceso de destrucción de industria. Pero hacia fines de la década de 1980, además de un proceso de democratización, se produjo un proceso de agotamiento del modelo de sustitución de importaciones, lo que indujo a una crisis económica. Así, también los brasileños atravesaron una crisis financiera vinculada al sector externo, que llevó a las autoridades a repensar la estrategia de política exterior. Al igual que la Argentina, la década siguiente se caracterizó por ser neoliberal en lo económico y la consecuente desregulación del aparato económico nacional. La inserción global fue en ese sentido similar a la Argentina, en su mayor acercamiento al mundo liberal e institucional imperante, la participación en organismos internacionales, y la firma y ratificación de tratados de no proliferación. Sin embargo, luego del gobierno de Collor de Melo, el gobierno de Cardoso fue partidario

14 Existieron factores políticos y económicos para la toma de decisión, pero aquí consideramos los estructuralmente relevantes a partir de nuestro enfoque geopolítico del Orden Mundial en contexto semiperiférico. En efecto, en la década de 1990 Argentina y Brasil atravesaron una coyuntura económica difícil, con crisis en la macroeconomía, contexto de reformas neoliberales y ajuste fiscal, que afectó a la sociedad en su conjunto y las decisiones de política doméstica e internacional buscando la ayuda de Estados Unidos, superpotencia emergente tras la caída de la Unión Soviética. 
de un perfil más multilateral, y regional, buscando un Brasil con un rol global más importante, sin abandonar las políticas neoliberales (Saraiva \& Tedesco, 2001). Cardoso buscó sustituir la agenda de la política exterior, hasta entonces basada en la autonomía a través de la distancia, buscando una nueva agenda proactiva con una lógica de autonomía a través de la integración. Todo, a partir de las pautas de conducta del nuevo orden internacional (Vigevani et al., 2003).

En suma, ambos países modificaron su política externa de acuerdo a los procesos de política doméstica y la coyuntura mundial, signada por el fin del conflicto entre el capitalismo liberal estadounidense y el comunismo soviético, y los nuevos escenarios planteados a partir de esta realidad. En la década de 1970 primaba la rivalidad, pero eso comenzó a cambiar cuando las dictaduras militares fueron terminando. Consecuentemente, los perfiles de inserción internacional buscaron estar más abiertos hacia los Estados Unidos, institucional y multilateral (Bernal-Meza, 1998). Sumado a esto, ambos países hicieron un cambio en sus políticas en el año 2003, en los gobiernos de Kirchner y Da Silva. Ambos gobiernos tomaron un perfil más regional, de integración estratégica, leyendo los procesos políticos internacionales y regionales de manera similar, y persiguiendo la integración estratégica regional. Por esas razones, no solo el Mercado Común del Sur (MERCOSUR) tomó relevancia en el proceso de integración en este nuevo regionalismo sudamericano, sino también instituciones como la Unión Sudamericana de Naciones (UNASUR) (Bizzozero Revelez, 2012).

\subsection{El caso espacial argentino}

El caso de la política de tecnología espacial en la Argentina ha sido ampliamente trabajado por Blinder (2015a; 2015b). La consolidación de la política espacial reciente está vinculada a un misil y una institución. La Comisión Nacional de Actividades Espaciales (CONAE) fue creada a partir de la cancelación del proyecto "Misil Cóndor II", que era un misil de mediano alcance y de dos etapas con combustible sólido. El decreto presidencial de la creación de la agencia espacial expresa explícitamente la suspensión del Cóndor. La historia de este vector se remonta a la última dictadura de este país. En el período 1976 a 1983 se decidió emprender el proyecto dentro del secreto militar, para poder contar con capacidad de disuasión. El Cóndor fue financiado por empresas de Alemania, Francia e Italia, así como también de Irak y Egipto, lo que encendió las alarmas de proliferación de las potencias, especialmente de Estados Unidos. Durante el gobierno de Alfonsín, entre 1983 y 1989 el proyecto continuó en secreto, pero la crisis económica estancó su continuidad.

El gobierno de Menem, entre los años 1989 y 1999, se caracterizó por su pragmatismo en materia de política internacional ante la emergencia de los Estados Unidos como superpotencia tras la desaparición formal de la Unión Soviética. En ese sentido, el misil Cóndor resultaba un asunto irritante en las relaciones bilaterales de Argentina con los estadounidenses, y el presidente tomó una decisión de política exterior basada en argumentos de política tecnológica: terminó con el proyecto Cóndor, firmó y ratificó todos los tratados internacionales de no proliferación misilística y nuclear, manifestó su apoyo a la política exterior del entonces presidente Bush, y creó la agencia CONAE cuyo objeto era promover el desarrollo pacífico de tecnología espacial. 
El gobierno de Menem promovió la apertura económica y la equivalencia del peso argentino con el dólar, lo que redundó en la destrucción del entramado industrial, profundizando los lineamientos de la economía de la dictadura precedente, y se practicó una política exterior denominada "realismo periférico", consistente en una praxis de política externa consciente del lugar periférico que ocupa el país y de los costos de confrontación con los poderosos, entre ellos, sostener elementos irritantes para la relación (Escudé, 1992).

En las alianzas estratégicas con la NASA y con políticas activas que buscaron construir una buena relación con el gobierno estadounidense, la Argentina lanzó el satélite experimental $\mu$ SAT-1 Víctor en 1996, el SAC-B en 1996 para estudiar el Sol, el Nahuel-1A en 1997, el SAC-A en 1998 con objetivos experimentales, el SAC-C en 2000 para observación terrestre. Todos estos satélites fueron lanzados por cohetes de otros países, es decir, terceros actores que alquilaron el servicio de lanzamiento satelital.

Desde la creación de la CONAE, la política exterior parece dar sus frutos: si relacionamos la cantidad de logros tecnológicos desde antes de la creación de la agencia, y a partir de la creación de la misma, se puede argumentar que el país se ha desarrollado espacial y tecnológicamente. Con una política como la del misil Cóndor es improbable que la Argentina pudiera haber tenido esta performance. Pero hay que admitir que ésta se impulsó aún más con el proyecto industrializador que se inicia en 2003. A partir de los períodos estudiados, parece surgir la necesidad de una política pública y de una política exterior responsable, y una política industrial y tecnológica que la acompañe. Todas estas políticas en su conjunto forman parte de una gran estrategia política de desarrollo nacional (Blinder, 2017).

\subsection{El caso espacial brasileño}

Brasil tiene un proceso de construcción institucional en relación a los asuntos espaciales que nace en la década de 1960, en pleno contexto de conflicto entre los estadounidenses y soviéticos en el gran juego mundial entre potencias. Entonces surgió la Organizaço da Comissâo Nacional de Atividades Espaciais, que desarrollaba cohetes sonda de investigación metereológica. Ya en 1979 se creó la Missâo Completa Brasileira con el objetivo de dominar todo el ciclo de lanzamiento de un satélite, hasta la elaboración del mismo localmente. En 1994, finalmente, se creó la Agencia Espacial Brasileira bajo el Ministerio de Ciencia y Tecnología (Gonçalves de Araujo, 2014: 83-84). Una característica geopolítica que facilitó el asociativismo brasilero con terceros fue la base de lanzamiento de Alcántara, lo que facilitó negociaciones con países como China (satélites), Ucrania (cohetes) o Estados Unidos (cooperación con NASA).

La política tecnológica espacial en Brasil está enmarcada en un proceso que en algunos aspectos es similar a la Argentina en su trayectoria institucional: desarrollos en el ambiente militar con diversos propósitos, lo que incluía una visión estratégica de hipótesis de conflictos con los argentinos, un desarrollo de capacidades militares convencionales, nucleares y misilísticas (Batista, 2011), que luego devinieron en una agencia civil durante la década de 1990, con el objeto de tener un desarrollo pacífico, acorde a los acontecimientos que se sucedieron en el mundo después de la desaparición de la Unión Soviética, firmando tratados internacionales de no proliferación misilística y nuclear, la protección de la paz y el orden interes- 
tatal, y el libre mercado (Reis Pereira, 2008). No obstante ello, la política espacial brasilera está matizada por las cuestiones de uso dual de la tecnología, el proyecto de industrialización y sus cadenas de valor, la defensa del país, las declamaciones de soberanía y las relaciones con otros países en pos de conseguir el poder nacional.

El Programa Nacional de Atividades Espaciais (2012-2021) de Brasil plantea que la soberanía y la autonomía de un país está relacionada con su capacidad científico-tecnológica, y la tecnología espacial juega un rol preponderante en este escenario. A diferencia de Argentina, Brasil no tuvo un proyecto desindustrializador tras el golpe militar de 1964 contra João Goulart, que perduró hasta 1985. Pero en las décadas de 1980 y 1990 - al igual que en el caso argentino - existió primero una crisis económica y social profunda, y luego una etapa de apertura económica neoliberal. Recién en los gobiernos de Lula Da Silva (2003-2011) —y después en los de Dilma Rousseff - se desarrolló desde el gobierno una política estratégicamente industrialista con el objeto de consolidar a Brasil como una potencia emergente global. En esa línea, la Agencia brasilera busca dominar la tecnología espacial para tener, en palabras de su propio documento de política del sector, plena soberanía y autonomía, en relación al acceso a tecnologías críticas y de difícil acceso en el concierto internacional (Agência Espacial Brasileira, 2012: 3).

Según el mismo documento citado, el objetivo es impulsar el avance industrial (Agência Espacial Brasileira, 2012: 7) por lo que existe una visión estratégica cuyo objetivo es consolidar el desarrollo industrial, la innovación, la competitividad, la integración del mundo académico en el desarrollo, la cooperación con otros países, la articulación público/privada, la gobernanza de la política espacial y tecnológica en general, generando un marco legal acorde y la difusión entre la opinión pública nacional (Agência Espacial Brasileira, 2012: 8).

El mismo documento de la Agencia sostiene que es necesario el desarrollo del sector para lograr una eficaz política de telecomunicaciones, protección ambiental, marítima, de vigilancia de fronteras, por lo que alude también al usufructo de las instituciones castrenses de la tecnología espacial. Pero los hacedores de política de Brasil manifiestan algo que en los documentos argentinos no está explicitado, a saber, que existen barreras erigidas por ciertos países que impiden el acceso al conocimiento y la comercialización de tecnología espacial, y paralizan - por ser tecnologías críticas o sensibles - el desarrollo pacífico de lanzadores y satélites. Estas tecnologías se muestran en el sistema interestatal como disruptivas (Agência Espacial Brasileira, 2012: 11-12). Adicionalmente, en una revista académica de oficiales superiores del país sudamericano de habla portuguesa se plantea específicamente que el Programa Nacional de Actividades Espaciales es un factor estratégico para la Defensa Nacional y el desarrollo (Gonçalves de Araujo, 2014: 81).

El Livro Branco de Defesa Nacional (Ministério da Defesa, 2012) es el documento público vinculado al área de la política de Defensa, y con respecto al uso del instrumento militar, más importante de Brasil. A diferencia del Libro Blanco argentino, especifica capacidades de tecnología espacial para el uso militar. En la Argentina, hasta fines de 2015 el Sistema Nacional de Ciencia, Tecnología e Innovación incluía al Sistema Científico y Tecnológico para la Defensa (Ministerio de Defensa, 2015: 155; 172). Este incluía a la CONAE, institución que hace énfasis en la secularización de cualquier tema vinculado al uso bélico (Blinder, 2015b). Contrariamente, el Livro Branco plantea que el principal proyecto espacial es el 
Vehículo Lanzador de Satélie (Ministério da Defesa, 2012: 72), es decir, un cohete, aquello que resulta más controversial a la hora de la diplomacia global, puesto que en su uso dual podría constituir un misil. Brasil parece no tener mayores problemas en plantearlo abiertamente, habiendo firmado, al igual que la Argentina, el MTCR $^{15}$ con el objeto de garantizar la no proliferación misilística. En este Livro se destacan además de diversos misiles de uso específico militar, los cohetes VLS-1 V1, VLS-1 V2, VLS-1 V3 con sus satélites proyectados correspondiente, SCD-2A, SACI2, SATEC respectivamente. En la Argentina, el vehículo lanzador en desarrollo Tronador y sus versiones de prueba de sistemas VEX, son de uso exclusivo civil. En Brasil, se integran con el sistema defensivo para cubrir la vacante de la protección de recursos naturales, fronteras, inteligencia, etc., que incluye el Sistema de Administración de la Amazonia Azul, Sistema Integrado de Monitoreo de Fronteras, el Sistema de Control del Espacio Aéreo Brasileño, el Sistema de Defensa Aeroespacial y otros (Ministério da Defesa, 2012: 72-77).

Desde la academia anglosajona se presenta a Brasil como el país sudamericano con mayor desarrollo de tecnología espacial. El libro más importante publicado al respecto es el de Robert Harding que ve a Brasil como uno de los países emergentes junto a China e India como los más destacables del mundo en desarrollo (Harding, 2013: 2). Esta idea equivocada se repite en diversos textos en portugués sobre el propio Brasil, que destacan el desarrollo de este país como singular, a veces omitiendo o mencionando a la Argentina ocasionalmente. Sin embargo, el programa de desarrollo de tecnología espacial más sólido y más avanzado hasta la fecha es el argentino, con diversos satélites en el espacio, dos geoestacionarios producidos localmente, y en un estado avanzado de las pruebas para el lanzador Tronador II (Blinder, 2015a). El primer texto que reconoce este hecho es un artículo académico publicado en una Revista de la Fuerza Aérea de los Estados Unidos (Vilar Lopes, 2016: 24). El autor señala que los brasileños desarrollan tecnología espacial para tener poder nacional en el concierto internacional, en el mismo sentido que Harding (2013: 8), que le atribuye capacidad de generar empleos de alta tecnología, seguridad militar, capacidad de recolección de inteligencia, y del ejercicio de la diplomacia.

Una tesis de doctorado sobre política espacial brasileña (Reis Pereira, 2008) plantea que los asuntos relacionados con el desarrollo espacial pueden entenderse subdividiendo el proceso en distintos períodos, ligados a los vaivenes de la política doméstica. El primer período va desde 1961 a 1970, en el que participan distintas instituciones de aeronáutica brasileña, que formó distintos cuadros ingenieriles, luego capaces de desarrollar las tecnologías del campo. Asimismo, en coincidencia con Argentina, oficiales militares fueron enviados al MIT y a la Universidad de Stanford a estudiar y perfeccionar sus conocimientos. Entre 1971 y 1985 se consolida la institucionalización del sector, creándose la Comissâo Brasilerira de Atividades Espaciais, dependiendo de un organismo de seguridad nacional en el que participaban todas las fuerzas y otras instituciones vinculadas a la industria. Entre

15 El Missile Technology Control Regime fue creado en 1987 con el objetivo de limitar el desarrollo misilístico. El MTCR es una asociación de países "informal y voluntaria" en la cual los firmantes se comprometen a no desarrollar dicha tecnología. Los creadores de este régimen de control son Canadá, Francia, Alemania, Italia, Japón, Gran Bretaña, y los Estados Unidos, todos ellos países que cuentan con tecnología espacial y misilística. 
1985 y 2007 se produjeron las mayores transformaciones que repercutieron en la política espacial, en la cual la consolidación democrática y la crisis económica posterior y las reformas estructurales del Estado, determinaron que el presupuesto del sector y las actividades empezaran a ver sus frutos a partir del principio del nuevo siglo. Entre 1994 y 2007, se generó una sinergia entre los objetivos nacionales, la industria, y las necesidades espaciales con la participación de instituciones civiles y militares, teniendo un aumento presupuestario y apoyo político en el gobierno de Lula da Silva.

\subsection{El caso misilístico argentino}

La producción de misiles de la Argentina tiene varias décadas, es modesta, pero con algunos desarrollos. Uno de los misiles que este país ha desarrollado fue el CITEFA $^{16}$ AS-25K, de tipo aire-mar y aire-superficie. Este misil es un desarrollo del Martín Pescador MP-1000 aire-superficie, de principio de la década de 1970, y fue retirado dos décadas después para desarrollar el AS-25K. Otro misil guiado es el Mathogo (Misil Anti-Tanque Hilo Guiado) desarrollado por CITEFA.

El más importante de los desarrollos en términos de su envergadura fue el Gradicom 1 y 2, desarrollado bajo la órbita del Ministerio de Defensa. El número 1 tuvo por objetivo probar los motores. El número 2 era un misil/cohete de dos etapas de combustible sólido, con el objetivo oficial de constituirse en vector lanzador de objetos al espacio exterior. En efecto, no es un misil en sí, pero al ser desarrollado por una agencia de desarrollos militares y en el ámbito de la Defensa, y al no formar parte de la agencia oficial CONAE, asumimos aquí que se trata de un misil. Más aún, en una entrevista con los responsables del proyecto se ha manifestado las obvias características de su posible uso militar. Sin embargo, la legitimación del proyecto se debió al desarrollo de un lanzador propio para las distintas cargas útiles, entre ellas, el ARSAT, pero también como desarrollo enmarcado en el entonces proyecto de Agencia Espacial Sudamericana en el marco de la UNASUR.

El Cóndor II fue el desarrollo más importante, más arriba mencionado, y era un desarrollo de un misil balístico de alcance intermedio, desarrollado a partir del Cóndor I. Es interesante destacar que la Argentina no produjo una gran cantidad de variantes misilísticas, en parte quizás a una gran crisis económica, y por las condiciones en las que quedó tras la derrota en 1982 de Malvinas, cuando las negociaciones diplomáticas con Gran Bretaña y los Estados Unidos definieron un perfil no confrontativo del país, con un código geopolítico de realismo periférico.

\subsection{El caso misilístico brasileño}

Brasil tiene una mayor proliferación de desarrollos misilísticos en su nómina, y una importante trayectoria industrial y tecnológica para la defensa, producto de la tradición pro-industrial de sus clases dirigentes. Su empresa Avibras Indústria Aeroespacial es muy importante en el desarrollo tecnológico. Entre ellos, el MAA-1 Piranha, un misil de corto alcance, aire-aire. Este misil fue exportado a Colombia,

16 CITEFA es el acrónimo de Instituto de Investigaciones Científicas y Técnicas de las Fuerzas Armadas. Hoy en día se llama CITEDEF, acrónimo de Instituto de Investigaciones Científicas y Técnicas para la Defensa.

Ambos son dependientes del Ministerio de Defensa de la República Argentina. 
Indonesia y Pakistán. Otro es el aire-aire V3E A-Darter en un consorcio con Sudáfrica, y para equipar las aeronaves Saab JAS 39 Gripen del socio, así como helicópteros y aviones de la propia fuerza. Probablemente también, están proyectados para equipar los propios Gripen que serán fabricados en territorio brasilero con licencia de la empresa sueca. No es el único consorcio asociativo de Brasil en el campo militar y que incluye montar el misil A-Darter, pues este país sudamericano ha fabricado junto a Italia el AMX, un avión de ataque producido en la década de 1980. Otros desarrollos son el Mectron MSS-1.2, y el FOG-MPM (Fiber Optics Guided Multiple Purpose Missile) que es un misil antitanque, anti fortificación, y antihelicóptero, o el ASTROS II (Artillery Saturation Rocket System) que es un multilanzador de cohetes, que fue utilizado en conflictos internacionales, como la Guerra del Golfo (1990-1991).

En la categoría de misiles crucero, Brasil desarrolló el AVTM-300 (Avibrás Tatical Missile), pensado para remplazar a misiles estadounidenses. Otros desarrollos son el FOG-MPM (Fiber Optics Guided Multiple Purpose Missile), el MANSUP (Míssil Antinavio Nacional), el misil anti-radiación MAR-1 aire-superficie y superficie-superficie, o la bomba guiada SMKB que es capaz de operar tanto con el sistema estadounidense GPS, con el europeo GALILEO, o el ruso GLONASS ${ }^{17}$.

\subsection{Status quo militar y tecnológico}

Un Orden Mundial, dijimos, es aquel que se hace de instituciones que cristalizan las relaciones de poder en el sistema internacional. Dos regímenes internacionales que regulan la cuestión de las tecnologías sensibles son el Missile Technology Control Regime y el Wassenaar Arrangement. El primero tiene por objeto restringir la proliferación de misiles, ciertos sistemas de cohetes, vehículos no tripulados y tecnología afín, capaces de transportar una carga de $500 \mathrm{~kg}$ y transportarla a $300 \mathrm{~km}$, así como aquellos que fueron creados para cargar armas de destrucción masiva. El objetivo principal de esta institución es que los socios reconocen la importancia del control de la transferencia a terceros que puedan afectar el sistema internacional. Para ello, realiza reuniones y elabora listados de la tecnología sujeta a control.

El MTCR es un régimen informal que procede bajo los lineamientos de la Resolución 1540 de las Naciones Unidas ${ }^{18}$, fundado en 1987 por iniciativa de los Estados Unidos, y que incluía en ese momento a los países industrializados de occidente. Los miembros son Argentina (1993), Australia (1990), Austria (1991), Béligca

17 Ver la revista Defensa, 8 de noviembre de 2011 [URL: <http://sistemasdearmas.com.br/pgm/smkb.html>. Consultado el 12 de julio de 2016].

18 La Resolución 1540 del Consejo de Seguridad de la ONU dice “[...] Decide que todos los Estados deben abstenerse de suministrar cualquier tipo de apoyo a los agentes no estatales que traten de desarrollar, adquirir, fabricar, poseer, transportar, transferir o emplear armas nucleares, químicas o biológicas y sus sistemas vectores; Decide también que todos los Estados, de conformidad con sus procedimientos nacionales, deben adoptar y aplicar leyes apropiadas y eficaces que prohíban a todos los agentes no estatales la fabricación, la adquisición, la posesión, el desarrollo, el transporte, la transferencia o el empleo de armas nucleares, químicas o biológicas y sus sistemas vectores, en particular con fines de terrorismo, así como las tentativas de realizar cualquiera de las actividades antes mencionadas, participar en ellas en calidad de cómplices, prestarles asistencia o financiarlas; Decide también que todos los Estados deben adoptar y hacer cumplir medidas eficaces para instaurar controles nacionales a fin de prevenir la proliferación de las armas nucleares, químicas o biológicas y sus sistemas vectores, incluso estableciendo controles adecuados de los materiales conexos" (Resolución 1540 ONU). 
(1990), Brasil (1995), Bulgaria (2004), Canadá (1987), República Checa (1998), Dinamarca (1990), Finlandia (1991), Francia (1987), Alemania (1987), Grecia (1992), Hungría (1993), Islandia (1993), India (2016), Irlanda (1992), Italia (1987), Japón (1987), Luxemburgo (1990), Holanda (1990), Nueva Zelanda (1991), Noruega (1990), Polonia (1998), Portugal (1992), Corea (2001), Rusia (1995), Sudáfrica (1995), España (1990), Suecia (1991), Suiza (1992), Turquía (1997), Ucrania (1998), Reino Unido (1987), Estados Unidos (1987) ${ }^{19}$.

El Wassenaar tiene un objeto similar: el control de tecnologías de uso dual. Establecido con el fin manifiesto de contribuir a la seguridad regional e internacional, promoviendo la transparencia y la responsabilidad de los países en la fabricación, comercialización y transferencia de estas tecnologías, para que no sean poseídas con fines militares por países beligerantes o terroristas. Los miembros de esta institución son Argentina, Austria, Bulgaria, Canadá, Croacia, República Checa, Dinamarca, Estonia, Finlandia, Francia, Alemania, Grecia, Hungría, Irlanda, Italia, Japón, Letonia, Lituania, Luxemburgo, Malta, México, Holanda, Nueva Zelanda, Noruega, Polonia, Portugal, Corea, Rumania, Rusia, Eslovaquia, Eslovenia, Sudáfrica, España, Suecia, Suiza, Turquía, Ucrania, Reino Unido, y Estados Unidos. Incluye prácticamente a los miembros del MTCR y algunos países más, y fue establecido en el año 1996.

El Tratado de No Proliferación de Armas Nucleares fue establecido en 1968 bajo la órbita de la ONU, y establece en su artículo I que:

Cada Estado poseedor de armas nucleares que sea Parte en el Tratado se compromete a no traspasar a nadie armas nucleares $u$ otros dispositivos nucleares explosivos ni el control sobre tales armas o dispositivos explosivos, sea directa o indirectamente; y a no ayudar, alentar o inducir en forma alguna a ningún Estado no poseedor de armas nucleares a fabricar o adquirir de otra manera armas nucleares u otros dispositivos nucleares explosivos, ni el control sobre tales armas o dispositivos explosivos.

Esto significa, explícitamente, que aquellos con armamentos nucleares no están obligados a abandonarlos. Estos son los miembros permanentes del Consejo de Seguridad de la ONU, Estados Unidos, Reino Unido, Rusia, China, y Francia. El artículo II, postula que:

Cada Estado no poseedor de armas nucleares que sea Parte en el Tratado se compromete a no recibir de nadie ningún traspaso de armas nucleares u otros dispositivos nucleares explosivos ni el control sobre tales armas o dispositivos explosivos, sea directa o indirectamente; a no fabricar ni adquirir de otra manera armas nucleares $\mathrm{u}$ otros dispositivos nucleares explosivos; y a no recabar ni recibir ayuda alguna para la fabricación de armas nucleares u otros dispositivos nucleares explosivos.

Los únicos países que no han firmado el tratado son India, Israel, Pakistán y Sudán de Sur. Corea del Norte se retiró del tratado en 2003.

19 Ver URL: <MTCR.info>. Consultado el 16 de junio de 2016. 


\subsection{Institucionalidad internacional argentina}

La Argentina es miembro del TNP, del MTCR y del arreglo de Wassenaar. Al ser firmante del TNP, y al ser un Estado que desarrolla tecnología nuclear y la exporta, el país cumple con todos los requisitos formales de no proliferación y los practica en pos de la gestión tecnológica (Hurtado, 2014). Como signatario de Wassenaar ${ }^{20}$, el país transita los caminos burocráticos internacionales para conseguir el mismo objetivo en relación a cualquier tipo de armamento. En materia de Defensa, este Estado tiene como empresas el Complejo Industrial Naval Argentino, la Fábrica Argentina de Aviones, y Fabricaciones Militares. Entre otros institutos, está el Instituto de Investigaciones Científicas y Técnicas para la Defensa (CITEDEF), que tiene el propósito de desarrollar tecnologías vinculadas al sector.

La proliferación de misiles balísticos ha sido una de las cuestiones más importantes para la seguridad internacional, y uno de los hechos fundamentales para controlarla ha sido el MTCR, cuya misión ha sido vigilar la proliferación de misiles denegándole a potencias regionales la tecnología para construirlos (Mistry, 2003: 119). A comienzos de los años 1990, la Argentina renunció a sus derechos de contar con tecnología propia, en pos de tener buenas relaciones diplomáticas con el mundo unipolar. Los países desarrollados y más poderosos de la tierra cuentan con la tecnología que fomentaron controlar en el MTCR. Con respecto a las relaciones internacionales y la política exterior, el Plan Espacial fundamenta su existencia en la cooperación, con un énfasis puesto en diversos países del globo, con una institución sudamericana por entonces con pocos años de existencia, el MERCOSUR, el régimen de no proliferación misilística, MTCR, y el organismo de las Naciones Unidas relativo al espacio exterior, COPUOS. Todo esto está enmarcado en el viraje de la política exterior que realizó la Argentina durante la presidencia Menem, encuadrando al país en una política de cooperación activa con la gran potencia de aquellos tiempos, los Estados Unidos. En su artículo 3.3.1 el Plan Espacial 19952006 señala:

20 Desde una perspectiva política se podría evaluar que para consolidar las relaciones con los Estados Unidos, y en función de la prioridad que el gobierno de ese país le otorgaba a la desactivación del misil, no alcanzaba con detener el proyecto, sino que había que modificar todo el contexto de políticas y reglamentaciones vinculados con la importación, exportación y producción de tecnología sensitiva. En este marco la administración Menem produjo un giro altamente significativo, donde los cambios que se destacan son:

- la creación en mayo de 1991 de la Comisión Nacional de Actividades Espaciales (CONAE), que significaba que el control de las actividades espaciales en todos lo órdenes (científico, técnico, industrial, comercial, administrativo y financiero) pasaba al poder civil;

- la adhesión en mayo de 1991 al "Régimen de Control de Tecnología Misilística" (MTCR). Argentina ingresó formalmente al MTCR el 23 de agosto de 1993 al entregar en Washington al gobierno de Estados Unidos su nota de adhesión a ese foro. De esta forma ese gobierno invitó a la Argentina a participar formalmente de la reunión que dicha organización realizó en Interlaken, Suiza, el 29 de noviembre de 199329;

- el establecimiento en abril de 1992, un "Régimen de Control de Exportaciones Sensitivas" que reglamenta un estricto control sobre esas ventas al exterior;

- el ingreso en junio de 1992 al "Grupo Australiano", el cual establece controles en materia de exportaciones de substancias químicas y biológicas;

- el avance, entre el 29 de abril y el 1 de mayo de 1992, en la asociación argentina al "Comité de Coordinación para el Control Multilateral de Exportaciones" (COCOM)30;

- la firma en febrero de 1993 del Memorándum de Entendimiento entre Estados Unidos y Argentina. Por el mismo, nuestro país accedió al tratamiento favorable de los Estados Unidos respecto a las exportaciones de tecnología estratégica de ese país (Busso, 1994). 
La cooperación internacional es fundamental en el tema de la tecnología espacial. La Argentina cuenta con antecedentes de una prolongada y activa cooperación con la República Federal de Alemania, la República de Francia, la República Federativa de Brasil, los Estados Unidos de Norteamérica, la República de Italia, con posibilidades de concretar futuros proyectos con los Reinos de España y Dinamarca, y otros países. CONAE impulsará estas líneas de cooperación en tanto resulten convergentes con los desarrollos previstos en el presente Plan Espacial Nacional y sirvan para concretar proyectos que confluyan a metas bien definidas. CONAE considerará en una segunda prioridad aquellas iniciativas o propuestas de cooperación internacional que impliquen diversificar sus esfuerzos (CONAE, Plan Espacial 1995-2006) $)^{21}$.

Manifiestamente el Plan Espacial declara que la CONAE debe asistir al Ministerio de Relaciones Exteriores, Comercio Internacional y Culto en materia de convenios internacionales sobre el tema espacial. Asimismo, debe aportar los elementos técnicos que correspondan para una participación activa como miembro del Régimen de Control de Tecnología Misilística (MTCR) y en las reuniones de la Comisión Para el Uso Pacífico del Espacio Ultraterrestre (COPUOS) de las Naciones Unidas (CONAE, Plan Espacial 1995-2006). El uso de la política espacial está supeditado a una política activa de no proliferación de tecnología misilística, y a la política exterior que busca, en el marco de legitimación del Orden Internacional, un comportamiento activo para garantizar que no se produzcan este tipo de tecnologías en países no confiables o que no suscriban los postulados del Orden.

\subsection{Institucionalidad internacional brasileña}

El Brasil es miembro del TNP y del MTCR, pero no del arreglo de Wassenaar. Con respecto a esto último, es destacable observar que la industria militar de exportación del país de habla portuguesa es mucho más importante que la de Argentina. Las empresas de este país más importantes y que concentraban casi la totalidad de las exportaciones eran ENGESA, EMBRAER y AVIBRAS (Acuña \& Smith, 1994: 31). En el año 2013, el ministro de Defensa Celso Amorim, entregó el certificado de Empresa Estratégica de Defensa a 26 compañías que forman parte de la llamada Base Industrial de Defensa. Las firmas en cuestión son AEQ, Akaer, Armtec, Atech, Avibras, Axur, Bradar, Condor, Digitro, Embraer, Fligh Technologies, Emgepron, Grupo Inbra, Iacit, IAS, Imbel, Mectron, Nuclep, Opto Eletrônica, Orbital, Rustcon, Spectra, Taurus, Vertical do Ponto, BCA y Nitroquímica, siendo seleccionadas entre 81 que se habían interesado por unirse al programa certificado ${ }^{22}$.

21 “3.3.2. CONAE pondrá particular interés en afianzar la cooperación regional en materia espacial. Buscará ampliar las metas y optimizar las tareas previstas en el presente Plan impulsando una activa cooperación en el marco del MERCOSUR. Promoverá el uso de recursos complementarios de infraestructura y medios de desarrollo en la región, programará acciones de asistencia mutua, contemplará desarrollos complementarios y explorará la posibilidad de realización de misiones espaciales conjuntas" (CONAE, Plan Espacial 1995-2006).

22 Ver "Estas son las primeras 26 empresas estratégicas de Defensa certificadas por Brasil". Infodefensa, 28 de noviembre de 2013. [URL: <http://www.infodefensa.com/latam/2013/11/29/noticia-estas-primeras-empresasestrategicas-defensa-certificadas-brasil.html $>$. Consultado el 14 de julio de 2016]. 
En la historia de la tecnología nuclear de Brasil hay algunos hitos, cuya característica es estar signados por las relaciones del Norte con el Sur. La compra y construcción de reactores de investigación enmarcados en el programa "Atómos para la Paz" y la Guerra Fría, la creación de institutos de investigación del sector, y los acuerdos para el uso civil de la energía atómica fueron firmados con los Estados Unidos. Además, la adquisición de reactores de potencia ha creado controversia política interna - que se trasladó a la política exterior- por el enriquecimiento de uranio, el modelo tecnológico a seguir, etc. Más importante, el desarrollo de tecnologías ligadas al ciclo de combustible nuclear, las usinas, las estrategias de desarrollo autónomo, llevarán a presiones internacionales por proliferación, que redundarán en la firma de tratados (Ribeiro de Andrade, 2012). En efecto, según explicó Sábato, "la oposición de Estados Unidos al plan nuclear brasileño se fundamentaría en la necesidad de detener la proliferación nuclear, impidiendo que Brasil llegue a estar en condiciones de fabricar bombas atómicas [...]" (1978: 73). Así, todos los gobiernos brasileños - cualquiera haya sido su orientación política - se han negado a firmar el Tratado de No Proliferación (NPT). Los esfuerzos hacia la noproliferación se perciben como un medio por el cual los países desarrollados monopolizan la investigación nuclear y de ese modo impiden a los Estados menos desarrollados adquirir una de las tecnologías del futuro más sofisticadas y promisorias (Grabendorff, 1987: 521). Posteriormente, en 1997 firmó el Tratado, encuadrándose en esta política de inserción institucional mundial.

Brasil ingresó al MTCR en el año 1995, lo que significó un cambio de la política de este país en torno a la proliferación. Un año antes creó su agencia espacial, y procedió a establecer una serie de reformas políticas tendientes a la confianza internacional hacia el exterior. Se desactivó la agencia bajo control militar, se buscó mostrar una vocación civil de producción de la tecnología, y se canceló todo desarrollo de misiles con capacidad de portar armas de destrucción masiva. En la misma sintonía, a nivel regional, la Argentina había cancelado el programa del misil Cóndor y eso había abierto canales de diálogo. Por lo tanto, ambos países buscaban tener una política responsable hacia la comunidad internacional. Gracias al ingreso al MTCR, Brasil pudo importar, para el desarrollo de su vehículo lanzador de satélites, tecnología espacial de uso civil que antes le estaba vedada (Bowen, 1996).

\section{Reflexiones finales}

El presente trabajo tuvo como objetivo comprender el vínculo entre el Orden Mundial, la política exterior y la cuestión tecnológica desde una perspectiva geopolítica. Así, el desarrollo tecnológico de un país se vincula necesariamente con la inserción en el Orden, por lo tanto, la política exterior. Es imposible pensar el desarrollo tecnológico sin la variable externa, sus condicionantes, interacciones, negociaciones y conflictos. Si el Orden Mundial es institucional, entonces las políticas que apunten a ciertos desarrollos tecnológicos deberán mirar las cristalizaciones institucionales que no son más que la condensación en normas y burocracias en un momento de la historia, y que refleja relaciones de poder.

Cada país hace una lectura de ese Orden hacia el cual se elabora la política exterior, y que es también una decisión de política doméstica. Los códigos geopolíticos adoptados son, en ese sentido, aquellos que conforman la mirada y el lugar desde 
dónde se hace y para qué se hace dicha política. Con todo, deberíamos preguntarnos si entonces es legítimo hablar de una separación de política interna y externa, cuando no se pueden tomar decisiones de política local sin contar con la repercusión en la internacional. La geopolítica nos presenta una mirada con la cual los Estados son un actor más en el juego de poder, pero con el mero objetivo de una simplificación en el análisis hacemos una separación tajante adentro/afuera cuya realidad no se manifiesta en la práctica: lo global siempre incluye lo local y viceversa.

Lo local tiene instituciones nacionales y subnacionales, el Estado. Lo internacional, también, otras unidades estatales e instituciones. El factor geopolítico está atravesado por relaciones internacionales. Las Relaciones Internacionales son un factor más para analizar los mares por los que la geopolítica navega. La cuestión del desarrollo tecnológico, en la cual se ven las relaciones de poder, toma dimensión territorial y es regulada por instituciones estatales o supraestatales. El orden hegemónico es, por ese motivo, geopolítico. E incluye en su desarrollo a las relaciones entre naciones. Argentina y Brasil, como ejemplos de países en contexto semiperiférico, han tomado decisiones acorde a estos parámetros. Ambos desarrollaron tecnología espacial dentro de esa línea gris que divide el uso civil del militar. Ambos tuvieron planes de desarrollos duales, espacial y de misiles, y lo hicieron por percepciones estratégicas de la coyuntura regional y global. Los argentinos y brasileños, con los fuertes cambios geopolíticos de la década de 1990, y por razones internas, enmarcaron internacionalmente sus desarrollos y vieron los frutos de sus políticas.

Argentina, abandonó una política que resultaba irritante para las relaciones bilaterales con los Estados Unidos, y tuvo una política de participación institucional en organismos internacionales de no proliferación, se sometió a controles, y subsumió su política al ámbito civil, creando la CONAE por fuera de toda relación con los militares. Brasil, también creó su agencia civil y tuvo una política de cooperación e inserción con las instituciones internacionales, lo que también le facilitó el acceso a conocimientos y tecnología, y favoreció el desarrollo de los pilares de una política espacial nacional. Pero, aunque la Argentina tuvo un plan para hacerse de tecnología misilística, Brasil logró tener su aparato militar industrial más fortalecido y tuvo más logros en la materia. En cualquier caso, ambos con su política ganaron en gran medida la confiabilidad internacional, es decir, en el contexto que describimos, son confiables para las grandes potencias.

¿Por qué la tecnología? Porque nos permite observar en concreto la política en su dimensión geopolítica. ¿Qué muestra? La dimensión interna como externa - esta última como excluyente- para tener en cuenta en un análisis. La tecnología siempre es un factor determinante en las relaciones de poder. Con todo, la política exterior es un factor crucial para un Estado que quiera hacer una política tecnológica, ya sea omitiendo desarrollar tecnología por el perfil conflictivo que esto puede acarrear o ya sea desarrollando, y asumiendo los costos del desarrollo. ¿Qué nos dice la política de desarrollo misilística y espacial en contextos periféricos? Que hacer tecnología implica no solo contar con recursos técnicos y gerenciales, sino también políticos: la política de desarrollo tecnológica está condicionada por la política doméstica, la internacional, y buenas decisiones políticas sortearán y lograrán objetivos tecnológicos, no solamente buenos ingenieros, inversión, investigación, 
desarrollo y educación. El contexto periférico es central a la hora de entender, aún más, los condicionantes.

En el análisis de caso aquí presentado, tanto Argentina como Brasil han tenido una política hacia determinadas tecnologías que hemos tomado como ejemplo a analizar. Ambos países han optado por desarrollar tecnología espacial y misilística, y ambos han tenido distintos códigos geopolíticos que han determinado su política exterior, pero también han estado condicionados por la política dentro de cada una de las fronteras nacionales, en sus procesos histórico-políticos. Ambos han leído los aconteceres mundiales desde la década de 1950 y 1960, como una oportunidad dentro de la Guerra Fría, y ambos sufrieron golpes de Estado. Ambos también tenían una política exterior regional que miraba como hipótesis de conflicto la guerra con el vecino, y los desarrollos y carreras armamentística y tecnológica se encuadraban en ese contexto.

Con las dictaduras, Brasil en 1964 no proyectó una desindustrialización y búsqueda de capacidades autónomas. Por el contrario, Argentina en 1976 sí comenzó un proyecto de apertura y erosión del entramado industrial, pero los proyectos de desarrollo como el espacial tomaron cierto impulso, probablemente presionados por la coyuntura de la carencia de capacidades disuasivas posteriores a Malvinas. La coyuntura, y la actitud no conflictiva de Brasil con el bloque occidental, fue probablemente aquello que permitió el impulso de su industria militar. Los desarrollos espaciales y de misiles tuvieron la impronta de la institución castrense, así como en Argentina. En este último país, la pérdida de poder de los militares fue progresivamente en aumento producto de los fracasos bélicos, sociales y económicos que la dictadura dejó como saldo.

La década de 1980 profundizó la crisis económica de los dos países producto también de la economía internaciona ${ }^{23}$ y la década de 1990 con el nuevo escenario imperante, ambos países se adaptaron en su inserción con diferentes situaciones. Pero ambos se alinearon con los Estados Unidos y su política internacional, y participaron de la institucionalidad que este nuevo mundo proponía, de paz, seguridad internacional y no proliferación. Argentina y Brasil, condicionados por factores como la profunda crisis en sus economías locales, vieron debilitado su margen de maniobra político interno y externo, redundando en un argumento que reforzó la decisión de aceptar el ordenamiento geopolítico institucional global. En suma, ambos entendieron la existencia de un orden tecnológico, el cual también es sinónimo de Orden Mundial: en él han desarrollado sus políticas tecnológicas.

\section{Bibliografía}

Acuña, Carlos \& Smith, William (1994) "A Política da 'Economia Militar' no Cone Sul: Análise comparativa da democracia e da produção de armas na Argentina, no Brasil e no Chile. Contexto Internacional, vol.16, núm. 1, 7-52.

Agência Espacial Brasileira (2012) Programa Nacional de Atividades Espaciais - PNAE (2012-2021). Brasilia: Ministerio da Ciência, Tecnología e Inovação.

23 El Estado de Bienestar era puesto en cuestión en el bloque occidental, y la economía comenzaba procesos de apertura y desregulación, lo que se denominó neoliberalismo. 
Agnew, John (1995) Mastering Space; Hegemony, Territory and International Political Economy. Nueva York: Routledge.

Agnew, John (2005) Geopolítica. Una re-visión de la política mundial. Madrid: Trama.

Batista, Gabriela Ferro Firmino (2011) Politica externa brasileira e o Tratado de NãoProliferação de Armas Nucleares (TNP): da resistência à adesão. Dissertação (mestrado) - UNESP/UNICAMP/PUC-SP, Programa San Tiago Dantas. [Disponible en URL: $<$ http://hdl.handle.net/11449/96283>. Consultado el 23 de septiembre de 2016].

Bernal-Meza, Raúl (1998) "As relações entre Argentina, Brasil, Chile e Estados Unidos: política exterior e Mercosul”. Revista Brasileira de Política Internacional, vol. 41, núm. 1, 90-108 [Disponible en URL: <https://dx.doi.org/10.1590/S003473291998000100005>. Consultado el 14 de julio de 2016].

Blinder, Daniel (2015a) "Argentina space: ready for launch". Space and Defense Journal, vol. 8, núm. 1, 34-46.

Blinder, Daniel (2015b) "Hacia una política espacial en la Argentina". Revista Iberoamericana de Ciencia Tecnología y Sociedad (CTS), vol. 10, núm. 29, 65-89.

Blinder, Daniel (2017) "Argentina en el espacio: política internacional en relación a la política tecnológica y el desarrollo industrial". Revista de relaciones internacionales, estrategia y seguridad, vol. 12, núm. 1, 159-183.

Bowen, Wyn (1996) "Report: Brazil's accession to the MTCR". The Nonproliferation Review, vol. 3, núm. 3, 86-91.

CONAE. Plan Espacial Nacional 1995-2006. [Disponible en URL: $<$ http://www.conae.gov.ar/index.php/espanol/concursos/10-conae/plan-espacial/6planes-anteriores $>$. Consultado el 13 de enero de 2014].

Bizzozero Revelez, Lincoln (2012) "El MERCOSUR y el proceso sudamericano ante la segunda década del Siglo XXI: ¿Hacia una consolidación del nuevo regionalismo estratégico?". Si Somos Americanos, vol. 12, núm. 1, 215-237 [Disponible en URL: $<$ https://dx.doi.org/10.4067/S0719-09482012000100009>. Consultado el 14 de julio de 2016].

Busso, Anabella (1994) Anuario de Relaciones Internacionales. Cronología. [Disponible en URL: <http://www.iri.edu.ar/publicaciones_iri/anuario/A94/A1ANCRO.html>. Consultado el 13 de julio de 2016].

Cox, Robert (1994) "Fuerzas sociales, Estados y órdenes mundiales: más allá de la teoría de las relaciones internacionales”, en J. Vasquez (ed.) Relaciones Internacionales. El pensamiento de los clásicos. Barcelona: Limusa, 119-196.

Cox, Robert (1996) "Gramsci, Hegemony, and International Relations: An Essay in Method", en R. W. Cox \& J. Sinclair (eds.) Approaches to World Order. Cambridge: Cambridge University Press, 124-143.

Escudé, Carlos (1992) Realismo Periférico: Fundamentos para la nueva política exterior Argentina. Buenos Aires: Planeta.

Gonçalves de Araujo, Carlos (2014) "O Programa Espacial Brasileiro: uma oportunidade para o fortalecimento do poder nacional". Revista da Escola Superior de Guerra, vol. 29, núm. 58, 80-99.

Grabendorff, Wolff (1987) "La política nuclear y de no proliferación de Brasil". Estudios Internacionales, vol. 20, núm. 80, 520-568.

Harding, Robert (2013) Space Policy in Developing Countries: The search for security and development on the final frontier. Nueva York: Routledge. 
Hirsch, Joachim (1996) Globalización, Capital y Estado. México: UAM. [Disponible en URL: $<$ http://bidi.xoc.uam.mx/tabla_contenido_libro.php?id_libro=227 $>$. Consultado el 16 de junio de 2016].

Hurtado, Diego (2014) El sueño de la Argentina atómica. Buenos Aires: Edhasa.

Ikenberry, John (2001) After Victory: Institutions, Strategic Restraint, and the Rebuilding of Order after Major Wars. Princeton: Princeton University Press.

Jessop, Bob (2008) El futuro del Estado capitalista. Madrid: Catarata.

Kissinger, Henry (2001) La Diplomacia. México: Fondo de Cultura Económica.

Ministerio de Defensa (2015) Libro Blanco de Defensa Nacional. Buenos Aires: Ministerio de Defensa.

Ministério da Defesa (2012) Livro Branco de Defesa Nacional. Brasilia: Ministério da Defesa.

Mokyr, Joel (1990) The Lever of the Riches. Technological Creativity and Economic Progress. Nueva York: Oxford University Press.

Mistry, Dinshaw (2003) "Beyond the MTCR: Building a Comprehensive Regime to Contain Ballistic Missile Proliferation”. International Security, vol. 27, núm. 4, 119-149.

North, Douglas (1990) Institutions, Institutional Change and Economic Performance. Cambridge: Cambridge University Press.

Reis Pereira, Guilherme (2008) Politica espacial brasileira e a trajetoria do INPE (19612007). Dissertação (doutorado) - UNICAMP Programa de Pós-Graduação em Política Científica e Tecnológica, Universidade Estadual de Campinas . Instituto de Geociências. Disponible en URL: $<$ http://www.bibliotecadigital.unicamp.br/document/?code $=000433720>$. Consultado el 23 de septiembre de 2016].

Ribeiro de Andrade, Ana María (2012) “Átomos na política internacional”. Revista Iberoamericana de Ciencia Tecnología y Sociedad (CTS), vol. 7, núm. 21, 113-140.

Ruttan, Vernon (2006) Is War Necessary for Economic Growth? Military Procurement and Technology Development. Oxford: Oxford University Press.

Sábato, Jorge (1978) "El Plan Nuclear Brasileño y la Bomba Atómica". Revista Estudios Internacionales, año XI, núm. 41, 73-82.

Saraiva, Miriam Gomes \& Tedesco, Laura (2001) “Argentina e Brasil: políticas exteriores comparadas depois da Guerra Fria". Revista Brasileira de Política Internacional, vol. 44, núm. 2, 126-150 [Disponible en URL: <https://dx.doi.org/10.1590/S003473292001000200007>. Consultado el 14 de julio de 2016].

Schumpeter, Joseph (1971) Capitalismo, Socialismo y Democracia. Madrid: Aguilar.

Sombart, Werner (1943) Guerra y Capitalismo. Madrid: Colección Europa.

Taylor, Peter \& Flint, Colin (2002) Geografia política. Economía-Mundo, Estado-Nación y localidad. Madrid: Trama.

Vigevani, Tullo; Oliveira, Marcelo F. de \& Cintra, Rodrigo (2003) "Política externa no período FHC: a busca de autonomia pela integração". Tempo Social, vol. 15, núm. 2, 3161 [Disponible en URL: <https://dx.doi.org/10.1590/S0103-20702003000200003>. Consultado el 12 de enero de 2017].

Vilar Lopes, Gills (2016) "Brazil Space: military dependency and the case of the Geostationary Satellite of Defense and Strategic Communications". Space and Defense Journal, vol. 9, núm. 1, 22-38.

Wallerstein, Immanuel (2005) El moderno sistema mundial. Tomo I. México: Siglo XXI. 
Weber, Max (2002) Economía y Sociedad. Esbozo de sociología comprensiva. Madrid: Fondo de Cultura Económica. 